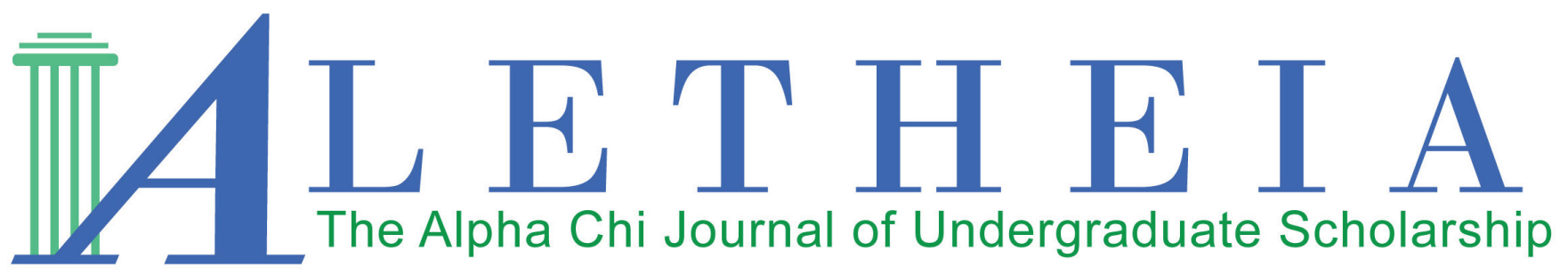

Volume 1 | Issue 2 | 2016

\title{
The Role of Breaking the Fourth Wall in Audience Ego Identification
}

\author{
Anne C. Stichter \\ Anderson University \\ Indiana Alpha Chapter
}

Vol. 1(2), 2016

Article Title: The Role of Breaking the Fourth Wall in Audience Ego Identification

DOI: $10.21081 / \mathrm{ax} 0011$

ISSN: $2381-800 \mathrm{X}$

Key Words: ego identification, theatre, fourth wall, audience

This work is licensed under a Creative Commons Attribution 4.0 International License.

Author contact information is available from the Editor at editor@alphachihonor.org.

\section{Aletheia-The Alpha Chi Journal of Undergraduate Scholarship}

- This publication is an online, peer-reviewed, interdisciplinary undergraduate journal, whose mission is to promote high quality research and scholarship among undergraduates by showcasing exemplary work.

- Submissions can be in any basic or applied field of study, including the physical and life sciences, the social sciences, the humanities, education, engineering, and the arts.

- Publication in Aletheia will recognize students who excel academically and foster mentor/mentee relationships between faculty and students.

- In keeping with the strong tradition of student involvement in all levels of Alpha Chi, the journal will also provide a forum for students to become actively involved in the writing, peer review, and publication process.

- More information and instructions for authors is available under the publications tab at www.AlphaChiHonor.org. Questions to the editor may be directed to editor@alphachihonor.org.

\footnotetext{
Alpha Chi is a national college honor society that admits students from all academic disciplines, with membership limited to the top 10 percent of an institution's juniors, seniors, and graduate students. Invitation to membership comes only through an institutional chapter. A college seeking a chapter must grant baccalaureate degrees and be regionally accredited. Some 300 chapters, located in almost every state, induct approximately 12,000 members annually. Alpha Chi members have been "making scholarship effective for good" since 1922.
} 


\title{
The Role of Breaking the Fourth Wall in Audience Ego Identification
}

\author{
Anne C. Stichter \\ Anderson University \\ Indiana Alpha
}

\begin{abstract}
This study aims to determine whether breaking the fourth wall through direct audience address increases the ego identification experienced by audience members during a play. Ego identification is the process by which an audience member vicariously follows a particular character through the plot. Research into audience response has been minimal, only beginning in the last several decades. Two different versions of a particular scene were staged; one maintaining the fourth wall and the other breaking it. Audience members completed a questionnaire recording their reactions to and emotions toward each character after each rendition of the scene. This paper hypothesized that there would be an increase in ego identification, according to four sub-hypotheses: 1) The higher the comfort of the audience member, the higher their average empathy ratings; 2) Breaking the fourth wall will increase the variation of selected favorite and most relatable characters; 3) Breaking the fourth wall will increase the overall empathy ratings for each character; and 4) Breaking the fourth wall will alter participants' selected favorite and most relatable characters. The first hypothesis was the only hypothesis to be supported in this sample $(p=0.01)$. Although the observed differences were not significant, the data suggest an overall increase. Reflections on the study's design yielded suggestions for a more sophisticated experimental design that might yield significant results in support of the use of breaking the fourth wall to increase ego identification and thereby further the purpose of theatre.
\end{abstract}

Key words: ego identification, theatre, fourth wall, audience

Theoreticians have debated and altered the roles, rights, and responsibilities of the audience at a theatrical performance for as long as theatre has existed. From the religious festival-goers of Ancient Greece to the rowdy entertainment-chasers of Elizabethan England, the audience's role has vacillated between interactive and merely receptive. One thing, however, remains constant. As Shelley Orr states it, "the presence of an audience is the key component that constitutes a theatre event" (2006, p. 369). Whatever the theatrical context permits the audience to do, and to whatever extent they are able to influence the performance, they are required to be present in order for the event to qualify as theatre. This makes theatre unique among artistic forms; all art must be appreciated to have value, but theatre must be live and is defined by this quality of presence. It is surprising, then, that the amount of empirical research on the subject is so lacking.

Though empirical literature on the subject is minimal, theoretical works abound. A repeated theme from these is that the audience invariably 
affects the performance. Tzachi Zamir claims that the importance of their presence is due to the fact that theatrical embodiment (the representation of a character by an actor), is "accordingly relational," engaging "in a constant dialogue with something that lies outside the boundaries of the work-audience response" (2010, p. 240). By sitting down to a play, the audience enters into a kind of contract with the actors to temporarily believe what they present, a contract that they will continually evaluate throughout the performance. The relationship between spectator and spectacle has an important influence on the performance - in both its execution and its effect - and is itself deeply affected by the nature, mood, and previous experience of each audience member. Quite apart from the factors within the rehearsed play that may cause the show to be different every night, the influence of the audience ensures that no two performances will ever be the same, because no two audiences are ever the same.

In addition to having an effect on the performance, the audience is also the target for the piece of theatre's purpose. Theatre can and does entertain, educate, and provoke action depending on the intentions of the creative team, and in each case they aim to do these things to the audience. In Theatre of the Oppressed, Augusto Boal outlines his interpretation of the purposes for which governments and artists have utilized theatre since Ancient Greece. In his view, Aristotle's Poetics advocates its use as a tool for subduing the masses, purging them of instincts and values that threaten the status quo. In contrast, Bertolt Brecht created theatre that demonstrated how the world could and ought to be changed, prompting the audience to go out and change it. Finally, Boal himself argues for the use of theatre to rehearse revolution (1974/1985). In each of these situations, the audience's role during the performance is very different:

Aristotle proposes a poetics in which the spectator delegates power to the dramatic character so that the latter may act and think for him. Brecht proposes a poetics in which the spectator delegates power to the character who thus acts in his place but the spectator reserves the right to think for himself, often in opposition to the character...the poetics of the oppressed focuses on the action itself: the spectator delegates no power...he himself assumes the protagonic role. (1974/1985, p. 122)

Depending on the purpose of the theatrical piece, the role of the audience and the form of the theatrical performance will vary greatly. Bertolt Brecht, whose plays and performance style broke with contemporary theatrical traditions, stated that this new form of theatre was tied to "a complete change of the theatre's purpose" (1964, p. 30). Purpose and form are closely linked. What form, then, is most effective for which purpose? If the purpose of a play is to influence or provoke the audience, what degree of interaction with them will produce the desired result?

The existence of theatre through the millennia stands, perhaps, as the strongest testament to its power and influence over humankind. Stories can provoke and change us as they entertain us, and theatre theory agrees that the reason for this lies in ego identification. This is the process by which a spectator will follow the action of the plot vicariously through a particular character, either because they wish to or currently resemble that character, or because the character gains rewards that the spectator desires. It is also one of the mechanisms employed from childhood to create identity through a pattern of imitation and dissociation from surrounding role models. These role models exist both in reality and in stories, and both contribute to the formation of identity. In the case of theatrical stories, when we experience them "we do not merely take in the thing/being, but also some of what she/he/it can become" (Zamir, 2010, p. 229). Ego identification is central to human learning, and in theatre it allows the message of a piece to impact its audience.

Aristotle's theory of tragedy and the importance of catharsis depends on this mechanism. As Boal describes it, the Aristotelian system depends on the fact that "from the moment the performance begins, 
a relationship is established between the character... and the spectator... Since the character resembles us...we live vicariously all his stage experiences" (1974/1984, p. 34). The trait to be purged (the tragic flaw) is presented first as the source of the protagonist's success, making it desirable, but is then revealed as the cause of the character's downfall. The connection between the character and the spectator takes them on the former's journey together, so that the pity and fear aroused by the character's plight will purge the spectator of the specific trait that caused it. In this way, the power of ego identification can teach, correct, and even change the spectator. Whether or not, as Boal states, the purpose of this is to "bridle the individual, to adjust him to what pre-exists" (1974/1985, p. 47), the Aristotelian model is certainly didactic. The issue with didactic theatre is that it presumes that playwrights, actors, and directors have the right or authority to teach and correct their audience through a powerful mechanism that can bypass reason and motivate through empathy. The use of theatre in this way is somewhat arrogant and undemocratic. Boal feared its capacity to enable the ruling classes to prevent impending change, but its capacity to subtly indoctrinate is of equal concern. Is there a less deceptive and didactic way to communicate the intended message?

A factor that greatly affects the effectiveness of ego identification is aesthetic distance, the psychological "distance" the audience has from the piece, which exists between two extremes: over-distance and under-distance. In over-distance, the features of the performance reveal its fallacy and break the illusion, causing the audience members to disengage from the story and characters. Under-distancing is caused by some aspect of the performance seeming too real; it causes the spectator to pull herself out of the illusion, restoring the boundary between fiction and reality. Either of these extremes can severely interrupt ego identification, which relies in part on the belief that the events surrounding the character are real, or at least believable. Agnes Sophie Bauer claims that "the tendency to over-distance as well as the tendency to under-distance ultimately eliminates theater" (1997, p. 152). In theatre that aims to enable the spectator to immerse herself into the plot, it may be best to maintain a midpoint between the extremes.

Conversely, Bertolt Brecht is famous in theatre theory for encouraging and even demanding that his audiences think during his plays. The danger of immersive, Aristotelian theatre, from which Brecht deviated, is that the empathy between character and spectator causes the real person to allow a fictional one to make decisions for them. As Boal put it, "this makes man (the real one) choose according to unreal situations and criteria" (1974/1985, p. 113), affecting his values and choices subtly. Brecht employed techniques such as direct audience address to create the alienation effect (Verfremdungseffekt), making the audience aware of the spectacle of theatre so that they would not become caught up in identification with the characters and would instead be compelled to think about the piece. He believed that "the one tribute we can pay the audience is to treat it as thoroughly intelligent" and that "the audience has got to be a good enough psychologist to make its own sense of the material...put before it" (Brecht, 1964, p. 14). Other theorists such as Ken Cartwright claim that detachment from the piece and from the characters (of the kind Brecht aimed for), "invites consciousness of the open moment of a protagonist's choice" (1991, p. 10). Awareness of the piece can actually "heighten [the spectator's] experience of the character" by engaging their reason as well as their emotions in the process of ego identification (Cartwright, 1991, p. 3). Augusto Boal also argues, "a good empathy does not prevent understanding and, on the contrary, needs understanding" (1974/1984, p. 103). This suggests that breaking the illusion of the piece may actually permit the audience to engage rationally as well as emotionally with the characters, and as a result empathize with them more without thoughtlessly taking on their values and opinions. Doing so would enable the creators of theatre to use the power of theatre less didactically and deceptively. 
A classic way in which performers can under-distance their spectators and make them aware of the fact of the spectacle is by talking to them directly; in theater theory, this action is termed "breaking the fourth wall." The "fourth wall" is the invisible line that separates the stage from the audience, named for the imaginary fourth wall of the room in which the play might be set, "through which the audience was to miraculously witness a slice of life" (Bauer, 1997, p. 139). Breaking the fourth wall can involve simply speaking directly to the audience or it can extend to interacting with them, to the point of inviting them to participate. For the purposes of this study, we will assume that breaking the fourth wall involves at least some degree of interaction beyond simply addressing the audience.

With history and theory in mind, we must ask if breaking the fourth wall is likely to increase ego identification. It can be unpleasant and uncomfortable to be addressed by an actor and be expected to respond, and it is likely that it will severely interrupt the process of ego identification. This will change the audience member from a passive observer, who has delegated the power of action to the character with whom he is identifying, to an active participant, who must make choices for himself. Will taking an active role increase the effect of the story and its message on the spectator-participant or decrease it?

An important factor in answering this question is the nature of the audience's expectations. Rarely does humankind like to have its expectations thwarted or betrayed, and "the spectator arrives with a bag of assumptions and expectations, which directly affect how s/he will construct the meaning of the performance" (Bauer, 1997, p. 134). Most audiences expect the fourth wall to be maintained, due to the dominant form of present day theatre, as well as the prominent influence of film and television, where an actor speaking directly to the camera certainly happens, but is used sparingly in order to make a specific statement. There is an unfortunate absence of research concerning which groups are most responsive to interactive theatre, information which would be beneficial to determine. The flouting of expectations is a dangerous business in any form of social interaction, and theatre audiences, "are known to react violently when the play they are watching does not follow the "rules of the game"" (Bauer, 1997, p. 131).

This study aims to explore the relationship between breaking the fourth wall and the resulting ego identification. Experimental research concerning this topic is virtually non-existent, and there is therefore little guidance as to how best to conduct it. I have chosen to do so by staging two versions of the same scene, one with the fourth wall intact and the other with it broken, and observing the differences between the audience's response to and evaluation of each. I propose an overall hypothesis that breaking the fourth wall will increase ego identification, except when it leads to disengagement. Audience members who are more comfortable with being addressed by the actors will be able to engage both rationally and emotionally as they ego identify with a particular character. Recognizing the complexity of the issue, I also posit four sub-hypotheses, which will help measure ego identification and the audience members' reaction to the form through responses on a questionnaire. First, I propose that the more comfortable audience members are with the breaking of the fourth wall, the higher their average empathy ratings will be. Being at ease with the form will enable better identification, while discomfort with the form will lead to over-distancing and disengagement. Second, breaking the fourth wall will increase the variation of favorite and most relatable characters. If breaking the fourth wall increases ego identification, then the natural variation in characteristics, opinions, and preferences between audience members should be reflected in their choice of ego identification targets. While they may agree on who is most likeable and relatable when the fourth wall is not broken, the increase in ego identification when it is broken should reflect a more equal distribution. Third, empathy for all characters will increase in the second version. Breaking the fourth wall enables audience members to relate interper- 
sonally to the character/actor, as well as rationally engage with the situation; this will lead to an increase in empathy. Fourth and last, breaking the fourth wall will alter the selected favorite and most relatable characters. The increase in ego identification caused by breaking the fourth wall will present stronger targets for ego identification than in the version that maintains it, and a change in selection will reflect this.

\section{Participants}

\section{Method}

The participants were from two groups: one, a group of college students receiving class credit for participating, and two, the audience and cast of Anderson University's production of The Magic Flute, who were invited to stay after the performance one evening. There were 80 total participants, including 54 women and 26 men. I grouped ages in ranges, and ranges were represented from 10-20 through 80 and above. Sixty of the participants were aged between 10 and 30; twenty were aged between 31 and 80 and above. Typical theatre attendance ranged from 0-2 times per year through 10 and above times per year.

\section{Materials}

I designed a questionnaire and distributed two copies to each participant with an information and consent form at the beginning of the event (see Appendices $\mathrm{B}$ and $\mathrm{C}$ ). The questionnaires were on a separate sheet of paper from the consent form to preserve anonymity and were printed on a single double-sided page so that the change across the two versions could be measured for each participant. The questionnaire included a section asking for demographic details, including age range, gender, and typical theatre attendance. The second part of the questionnaire included questions designed to measure empathy with each of the characters, favorite characters, most relatable characters, and comfort and interest in the performance.

\section{Procedure}

I rehearsed two versions of a scene from William Shakespeare's A Midsummer Night's Dream. I chose this scene because Shakespeare's work lends itself well both to traditional and interactive performance styles. The first version maintained the fourth wall and involved no audience interaction or acknowledgment. The second was highly interactive, employed direct audience address at every opportunity, and invited audience members to respond and help direct the course of the performance.

Information and consent forms and questionnaires were distributed as participants arrived. I explained the purpose of the study and defined the terms "ego identification" and "breaking the fourth wall" in order to provide a context for those who had agreed to participate. The difference between the scenes was also described, and participants were invited to ask questions for clarification. Participants watched the first, non-interactive version and completed Questionnaire 1. I then reminded them that the second version would be much more interactive, and invited them to contribute to and interact with the scene as it unfolded. After the second version was performed, the participants completed Questionnaire 2.

\section{Results}

I tested each hypothesis individually from the data obtained.

Hypothesis 1 posits that the more comfortable audience members are, the higher their average empathy will be. The average empathy score for each participant was calculated by taking the average rating for each of the four characters. A Pearson $r$ correlation coefficient was calculated between the average empathy rating and the comfort score for the first version and for the second $(\alpha=0.05)$. In both versions, the correlations between average empathy and level of comfort were identical and positive $(r=0.31, p=0.01)$. This indicates that empathy is likely to increase with level of comfort. It is interesting to note that average empathy ratings peaked not at the highest comfort rating ("Totally 
at Ease"), but slightly lower at "High." It is possible that very high comfort is indicative of decreased engagement; additionally, the crisis experienced by a character, if the audience member is truly engaged, could theoretically decrease comfort. This relationship would be interesting to explore in further research.

Hypothesis 2 proposes that breaking the fourth wall will increase the variation of favorite and most relatable characters. A chi-square test was run to determine the change in percentage distribution $(\alpha$ $=0.05)$. The difference observed for chosen favorite characters was not significant $(\chi 2(3)=5.155, p$ $=0.161)$. The observed difference for chosen most relatable character was also not significant $(\chi 2$ (3) $=2.399, p=0.494)$. Within this sample, therefore, breaking the fourth wall did not increase the extent to which the four characters were equally preferred or related to across the audience.

Hypothesis 3 anticipates that empathy ratings for all characters will increase in the second version. A dependent $t$-test was run to determine if there was a significant difference between the average empathy ratings for each of the two scenes $(\alpha=0.05)$. As seen in Table 3, although average empathy ratings increased, they did not do so in a statistically significant way $(t(78)=-0.80, p=0.43)$.

Finally, hypothesis 4 predicts that breaking the fourth wall will alter the favorite and most relatable characters of participants. A binomial $z$-test was run to determine whether the percentage of participants who changed their choice of favorite character and most relatable character was significant ( $\alpha=$ $0.05)$. Of the 80 participants, $53.75 \%$ changed their choice of favorite character and $41.25 \%$ did not. This result is not significant $(z=0.56, p=0.2877)$. In the case of most relatable character, however, only $40.00 \%$ of participants changed their choice of most relatable character, and $52.50 \%$ did not. This result suggests that audience members were actually significantly unlikely to alter their choice of most relatable character $(z=-1.68, p=0.0465)$.

\section{Discussion}

It is apparent from the results and the testing of each hypothesis that the overall hypothesis - that breaking the fourth wall would increase ego identification - is not supported within this sample on the basis of significance.

This may be due to certain assumptions about the nature of ego identification. In the second hypothesis, the theory that increased ego identification would lead to greater variation was purely theoretical, and further research is necessary to confirm it as an indicator of ego identification. It is possible that ego identification did increase, but that this was simply not an appropriate measure.

The fourth hypothesis, which predicted that participants would alter their choice of favorite and most relatable characters, was proposed on the basis that Version 2 would provide stronger targets for ego identification that would lead participants to select a character other than the narratively-preferred choice. In retrospect, however, it is counter-theoretical to propose that an audience member's target of ego identification would change. While possible, this would suggest that breaking the fourth wall initiates a different process of identification rather than strengthening the existing one. The design of the experiment also caused participants to make a selection after the first version, meaning they had formally chosen a particular character to identify with before the second version began. This effect should have been controlled for, either by finding a way to factor it in or by presenting two different scenes. The goal in presenting the same scene twice, however, was to control for the story, characters, and themes of the presented scene. Perhaps presenting the same scene to control and treatment groups would be the best way to achieve this. In any case, the resistance of participants' most relatable character choice suggests that this variable is linked to ego identification.

The lack of research in this area has made it difficult to determine not only the nature of the relationship between breaking the fourth wall and ego identification, but also the way to operationally 
define and measure it. This study has been experimental in this sense. In this trial, I assumed that ego identification is impossible without empathy, and that, therefore, ego identification is traceable to the target of greatest empathy. Robert Cartwright links identification and empathy directly, claiming that "engagement can range from simply identifying to identifying-with or empathizing," pairing "identification and empathy" as the highest level of engagement (1991, p. 13). Participants were also asked to select a favorite character and the character to which they related the most, both terms that connect to empathy and ego identification, and which may function as appropriate measures of each. It appears that the terms employed to measure ego identification were appropriate, though further research would allow the terminology to be refined.

A central issue with this study is the difficulty of bending theatre to the will of empiricism. While the absence of guiding research is frustrating, the scientific community cannot be blamed for avoiding an area of research that "requires the use of methods from other disciplines like sociology and empirical psychology," when "the origins of theatre studies lie in the humanities" (Bradley, 2013, p. 40). There is much theory about play and performance construction, but rarely have both empirical research and artistic expression been pursued, and it is a difficult thing to begin. Theatre does not lend itself to psychological research because it is unrepeatable, involves a complex web of interlinked variables that are hard to quantify or control, and can rarely be generalized to a population. It is, as Orr puts it, a process of "documenting the undocumentable" (2006, p. 369). In the event that a theatrical performance could be made exactly repeatable and that all variables could be controlled but the dependent variable(s), the event would hardly be theatre.

Theatre is an inherently unpredictable art, which proved true in this particular experiment, particularly when the audience was invited to respond and contribute. Had I anticipated the force of the response, the actors might have been better prepared to control the input; the audience was so loud, boisterous, and interactive that it was frequently difficult to comprehend the actors' words. Many modern phrases and elaborations were added to the original Shakespearean text, which, though entertaining, impaired the scientific integrity of the study. This meant that the two audiences did not see the same performances, and that the two versions of the scene were less similar than they were designed to be. This interfered both with repeatability and validity, preventing the participants from truly responding to the same stimulus and confusing what may have caused the observed differences. As stated above, the use of control and treatment groups could have circumvented these issues.

The process of this study has been enlightening for future research in this area, particularly concerning bending theatre closer to empiricism, and a number of guidelines have become apparent. First, it is essential to discourage deviation from the text outside of necessity. While line-dropping happens occasionally, conscious deviation must be avoided. Second, the study revealed that some audiences enjoy responding to and interacting with a piece. It is therefore imperative to train actors to control and guide audience interaction to ensure that the plot is able to proceed and that the text can be heard. Last, it is important to be aware of what will be termed the "run-of-the-show" effect. The outcome of each performance has a profound impact on the performances that follow; for example, actors will emphasize moments that received positive feedback the preceding night, thereby altering the way in which the moment was originally played and, most likely, the audience's response. It would therefore be advisable to limit the experiment to either one, or to more than two performances, thereby either preventing the run-of-the-show effect, or overcoming it with multiple performances.

In addition to these general guidelines for conducting research that involves theatre, improvements to this particular study and area of research were discovered. In an attempt to determine the best way to measure ego identification, this study measured too many variables across hypotheses 
that were too distinct. It would be more beneficial, reliable, and valid to address each hypothesis individually in the context of separate experiments.

As stated above, it would also be best not to play the same scene twice to the same audience. Ideally, two separate audiences should see only one version of the scene each, creating a control and a treatment group. It would be necessary to take measures to ensure that the audiences were sufficiently similar, and a greater total number of participants would be needed to achieve a representative sample. This design would remove many of the difficulties created by showing two versions to the same group without necessitating the presentation of two different scenes that would be difficult to match for similarity. With two distinct groups, it would be less important to explain the full purpose of the study in advance of the scenes; doing so in this study may have skewed results. With only one scene to watch, researchers would only need to tell the participants that the study was looking at creating empathy with theatrical characters. This design would also enable researchers to determine whether the scene has a natural target for ego identification. Characters in stories are rarely equally sympathetic, correct, or inspiring. The selected scene from A Midsummer Night's Dream approaches this equality, but certain characters are more sympathetic nonetheless. Identifying the most sympathetic characters through a control group could then inform the interpretation of the effects of breaking the fourth wall in the treatment group.

Another oversight was in the dimension of space; because the majority of audience interaction took place at the front of the house, closest to the stage, participants who selected seats near the back had a very different experience than those at the front. While this is common in theatrical venues, I did not ask participants to report the location of their seat, and as such it could not be determined how close to the spectacle they were, and therefore what effect physical distance may have had.

It would also be of interest to conduct this experiment with scenes from different genres and styles. I chose a Shakespearean comedy precisely because Shakespeare's work predates the concept of the fourth wall and has continued to be performed after it; its stories and texts are suited to both the acknowledgment and ignoring of the audience. The experiment would no doubt fare very differently, however, if it featured scenes from plays by Brecht, who intended to break the fourth wall during performance, or, conversely, plays from the Renaissance, when the fourth wall was deliberately enforced. An experimental design featuring scenes that specifically belong to one style or another would test the power of direct audience address and interaction to affect ego identification in a way that would be very informative.

In conclusion, the results obtained suggest that an increase in ego identification was present but not statistically significant when the fourth wall was broken. The study's limitations lie in its lack of repeatability and its undetermined validity, as well as a design that needs to be improved. However, these limitations have provided insight for the methodology of further research. The study also revealed other critical aspects of the subject, namely that this style of theatre is not effective for everyone and that comfort with the form and the piece has a definite impact on ego identification. The relationship between comfort and average empathy ratings, as well as the variation of self-reported comfort levels, suggest that it is important to prevent the audience from becoming either too comfortable or too uncomfortable if the goal is to produce ego identification.

Further research in this area will provide empirical support for the continued development of techniques, forms, and styles of theatre that will achieve the positive effects sought through Aristotelian catharsis without the passive loss of will feared by Brecht and Boal. This form will honor the audience's right and ability to process the morals and themes of a play for themselves while still engaging with stories and characters emotionally so that theatre may entertain, provoke thought, and inspire change. 


\section{References}

Bauer, A. S. (1997). Play-within-a-play and audience-response theory: A comparative analysis of contagious dramas by Gatti, Stoppard, and Weiss (Doctoral dissertation, Purdue University). Retrieved from Hicks Repository Closed Stack. (Thesis $43929 \mathrm{PhD}$ ).

Boal, A. (1985). Theatre of the Oppressed. (C. A. \& M. Leal McBride, Trans.). New York, NY: Theatre Communications Group. (Original work published 1974)

Bradley, L. (2013). East German theatre censorship: The role of the audience. Theatre Journal, 65(1), 39-56. Doi: 10.1353/tj.2013.0032

Cartwright, K. (1991). Shakespearean tragedy and its double: The rhythms of audience response. University Park, PA: Pennsylvania State University Press.

Orr, S. (2006). Performing opposition: Modern theater and the scandalized audience, and: Audience participation: Essays on inclusion in performance (review). Theatre Journal, 58(2), 369-371. Doi: 10.1353/tj.2006.0127

Willett, J. (Ed. \& Trans.). (1964). Brecht on Theatre. New York, NY: Hill and Wang.

Zamir, T. (2010). Watching actors. Theatre Journal, 62(2), 227-243. Doi: 10.1353/tj.0.0375 


\section{Appendix A}

Table 1

Paired samples statistics

\begin{tabular}{llllrr}
\hline & Mean & N & Std. Deviation & Std. Error Mean \\
\hline Pair 1 & EmpathyAvg_T1 & 3.1899 & 79 & .56076 & .06309 \\
& EmpathyAvg_T2 & 3.2532 & 79 & .79511 & .08946 \\
\hline
\end{tabular}

Table 2

Paired samples correlations

\begin{tabular}{llccc}
\hline \multirow{2}{*}{ Pair 1 } & N & Correlation & Sig. \\
\cline { 2 - 3 } & $\begin{array}{l}\text { EmpathyAvg_T1 \& } \\
\text { EmpathyAvg_T2 }\end{array}$ & 79 & .500 & .000 \\
\hline
\end{tabular}

Table 3

Paired samples dependent t-test results

\begin{tabular}{|c|c|c|c|c|c|c|c|c|c|}
\hline & & \multicolumn{5}{|c|}{ Paired Differences } & \multirow[b]{3}{*}{$\mathrm{t}$} & \multirow[b]{3}{*}{$\mathrm{df}$} & \multirow[b]{3}{*}{ Sig. (2-tailed) } \\
\hline & & \multirow[b]{2}{*}{ Mean } & \multirow{2}{*}{$\begin{array}{c}\text { Std. } \\
\text { Deviation }\end{array}$} & \multirow{2}{*}{$\begin{array}{l}\text { Std. Error } \\
\text { Mean }\end{array}$} & \multicolumn{2}{|c|}{$\begin{array}{r}95 \% \\
\text { Confidence Interval } \\
\text { of the Difference }\end{array}$} & & & \\
\hline & & & & & Lower & Upper & & & \\
\hline Pair 1 & $\begin{array}{l}\text { EmpathyAvg_T1 } \\
\text { EmpathyAvg_T2 }\end{array}$ & -.06329 & .70764 & .07962 & -.22179 & .09521 & -.795 & 78 & .429 \\
\hline
\end{tabular}




\section{Appendix B}

\section{Consent To Participate in Research}

\section{The Role of Breaking the Fourth Wall in Ego Identification}

You are asked to participate in this study by Anne Stichter, from the Honors Cohort at Anderson University as part of her Senior Project. Your participation is voluntary, and you are encouraged to read the information below and ask any questions or for clarification.

Purpose of the Study

To determine the effect of breaking the fourth wall (direct audience address) on ego identification (empathy with characters, idealization of character traits, etc.)

\section{$\underline{\text { Procedure }}$}

If you volunteer to participate, you will be asked to watch two versions of the same scene from a Shakespeare play and complete a questionnaire after each recording the scene's effect. The process will take no more than 25 minutes.

\section{Confidentiality}

Any information that is obtained in connection with this study and that can be identified with you will remain confidential and will be disclosed only with your permission or as required by law. Names of any participants will not be attached to data. The paper reviewing the results will be presented at the AU Scholars' Day Presentations and archived at Nicholson Library.

\section{Participation and Withdrawal}

You can choose whether or not to be in this study. If you volunteer to be in this study, you may withdraw at any time. You may also refuse to answer any questions you do not want to answer.

\section{$\underline{\text { Identification of Investigator(s) }}$}

If you have any questions or concerns, please contact Anne Stichter at acstichter@anderson.edu.

\section{Information about Results}

If you are interested in the results of this study, please contact Anne Stichter at acstichter@anderson.edu. You may also consult the Anderson University Nicholson Library Undergraduate Catalogue for a record of the full paper at the following address: http://palni.contentdm.oclc.org/cdm/landingpage/collection/p15705coll17 


\section{Consent to Participate in Research}

\section{The Role of Breaking the Fourth Wall in Ego Identification}

$\mathrm{I}$, , hereby agree to take part in this study.

I understand the procedures and purpose of this study and my questions and concerns have been addressed.

I authorize the information I provide to be used for research purposes. Date:

If you are participating in this experiment for class credit, please write the course name and the name of your professor below: 


\section{Appendix C}

\section{Questionnaire 1}

Please give the best answer for each question. Thank you for taking the time to contribute to this study.

Age:

$$
\begin{array}{lllllll}
10-20 & 21-30 & 31-40 & 41-50 & 51-60 & 61-70 & 71-80
\end{array}
$$

Gender:

$$
\text { Male Female }
$$

How often do you attend the theatre per year?

$0-2 \quad 2-5 \quad 5-8 \quad 8-10 \quad 10+$

Who was your favorite character?
Lysander
Demetrius
Hermia
Helena

Which character did you relate to most?

Lysander Demetrius Hermia Helena

Rate your level of empathy with each character.

Lysander

$\begin{array}{llll}\text { None } & \text { Low } & \text { Indifferent } & \text { Very High }\end{array}$

Demetrius
None
Low
Indifferent
High
Very High

Hermia
None
Low
Indifferent
High
Very High

Helena
None
Low
Indifferent
High
Very High

How comfortable were you during the performance?

Very unnerved Uncomfortable Fine Comfortable Totally at ease

How interested were you in the story?
Bored
Indifferent
Interested
Engaged
Captivated 


\section{Questionnaire 2}

Please give the best answer for each question. Thank you for taking the time to contribute to this study.

Who was your favorite character?
Lysander
Demetrius
Hermia
Helena

Which character did you relate to most?
Lysander
Demetrius
Hermia
Helena

Rate your level of empathy with each character.

Lysander
None
Low
Indifferent
High
Very High

Demetrius
None
Low
Indifferent
High
Very High

Hermia
None
Low
Indifferent
High
Very High

Helena
None
Low
Indifferent
High
Very High

How comfortable were you during the performance?

Very unnerved Uncomfortable Fine Comfortable Totally at ease

How interested were you in the story?
Bored
Indifferent
Interested
Engaged
Captivated

If you are interested in the results of the study, please email acstichter@anderson.edu. They will also appear in the Anderson University Nicholson Library records at this address: http://palni.contentdm.oclc.org/cdm/landingpage/collection/ p15705coll17 